\title{
O enriquecimento do vocabulário dos estudantes por meio da música em contos de fada no âmbito das práticas pedagógicas dos professores da educação básica
}

\author{
The enrichment of students' vocabulary through music in fairy tales within \\ the scope of the pedagogical practices of basic education teachers
}

Anaide Maria Alves da Paz

Mestre em Educação

Universidade de Pernambuco (UPE)

Nazaré da Mata, PE - Brasil.

anaidedapaz@hotmail.com

Maria de Fátima Gomes da Silva

Doutora em Ciências da Educação

Universidade de Pernambuco (UPE)

Nazaré da Mata, PE - Brasil.

fatimamaria18@gmail.com

Resumo: O presente artigo consiste em um recorte de uma pesquisa acadêmica que objetivava investigar perspectivas interdisciplinares da prática pedagógica de professores da Educação Básica do município de Nazaré da Mata, Zona da Mata Norte do estado de Pernambuco, por meio da música em contos de fada. O texto aborda especificamente o enriquecimento do vocabulário dos estudantes. A investigação, de natureza qualitativa, com ênfase na pesquisa-ação, teve como lócus três escolas públicas e como sujeitos três professoras e noventa alunos do quarto ano do Ensino Fundamental. A coleta de dados foi realizada mediante observação participante e oficinas pedagógicas. Os resultados permitiram concluir que as vivências interdisciplinares por meio da música em contos de fada, além de favorecerem o enriquecimento do vocabulário dos estudantes, contribuem para o desenvolvimento da oralidade, da leitura e da autonomia.

Palavras-chave: Escola. Interdisciplinaridade. Contos de fada. Música. Vocabulário.

Abstract: This article presents part of an academic research that aimed to investigate interdisciplinary perspectives of the pedagogical practice of Basic Education of Nazaré da Mata County's teachers, at Zona da Mata Norte in the state of Pernambuco, through music in fairy tales. The text specifically addresses the enrichment of students' vocabulary. The qualitative investigation, with an emphasis on action research, had as its locus three public schools, where three teachers and ninety students from the fourth year of Elementary School were subjected. Data collection was carried out through participant observation and pedagogical workshops. The results allowed us to conclude that interdisciplinary experiences through music in fairy tales contribute to the development of orality, reading, and autonomy besides favoring the enrichment of students' vocabulary.

Keywords: School. Interdisciplinarity. Fairy tales. Music. Vocabulary. 
PAZ, Anaide Maria Alves da; SILVA, Maria de Fátima Gomes da. O enriquecimento do vocabulário dos estudantes por meio da música em contos de fada no âmbito das práticas pedagógicas dos professores da educação básica

\section{Introdução}

Muitas são as ações interdisciplinares que podem ser viabilizadas na escola para o trabalho com contos de fada, desde a contação e recontação de histórias até o brincar de teatro e a recriação da narrativa com música, por exemplo. Assim sendo, essas alternativas possibilitam a vivência de projetos que venham a ser construídos com conteúdos de Artes, Língua Portuguesa, Música, História, Matemática, dentre outros componentes curriculares, resultando em novos conhecimentos, que podem ser adquiridos por intermédio de uma pactuação que envolva professor, alunos e objeto de conhecimento.

Os contos de fada também podem contribuir, inquestionavelmente, para promover o prazer da leitura, ampliando o interesse do estudante na descoberta de outras obras literárias. Além disso, propiciam o domínio do ato de ler e a aptidão da interpretação de textos, apropriações que possibilitam que o aluno conte a sua própria versão perante o que lhe foi possível perceber, desenvolvendo a sua autonomia e expandindo, consequentemente, o seu universo vocabular.

Nessa ótica, este artigo apresenta considerações acerca das contribuições da música em contos de fada para o enriquecimento do vocabulário dos estudantes. Diante disso, é necessário destacar duas elucidações. A primeira, diz respeito ao fato de que a música em contos de fada, neste trabalho, engloba as narrativas em que a música tem um papel preponderante. A segunda trata do sentido atribuído ao enriquecimento do vocabulário dos estudantes. Esta pesquisa não se ateve a identificar se os alunos tiveram novos acréscimos ao seu repertório de palavras ou expressões, pois essa ampliação quantitativa é um processo natural que faz parte da vida do sujeito, cuja temporalidade ultrapassaria a proposta investigativa. Assim sendo, o foco de atenção neste estudo teve como fundamento o tripé oralidade, leitura e autonomia.

Tendo em vista tais esclarecimentos, quanto à sua organização, o presente artigo assinala inicialmente os aspectos referentes à metodologia utilizada na investigação. Em seguida, são expostas as contribuições dos contos de fada para o enriquecimento do vocabulário dos estudantes do ensino fundamental, para, logo depois, analisar como esse enriquecimento se deu nas escolas públicas de Nazaré da Mata, enfatizando singularidades vivenciadas na Escola Castelo das Brincadeiras. Por fim, são apresentadas as considerações finais.

\section{Os procedimentos metodológicos}

O estudo ora apresentado foi orientado pela abordagem qualitativa de pesquisa, com ênfase na pesquisa-ação. Esse modelo de investigação privilegia a participação dos sujeitos, produzindo o compartilhar de conhecimentos e a construção de uma nova realidade baseada em novos 
PAZ, Anaide Maria Alves da; SILVA, Maria de Fátima Gomes da. O enriquecimento do vocabulário dos estudantes por meio da música em contos de fada no âmbito das práticas pedagógicas dos professores da educação básica

conhecimentos que emergem da relação entre teoria e prática, em que tantos pesquisadores quanto pesquisados aprendem. Em conformidade com os princípios da ética em seres humanos, o processo desta pesquisa se encontra registrado e aprovado na Plataforma Brasil sob o CAAE n. 79239417.0.0000.5207.

A investigação teve como lócus três escolas públicas do município de Nazaré da Mata, Zona da Mata Norte do estado de Pernambuco, as quais foram intituladas de "Escola dos Encantos, Contos e Canções", "Escola Castelo das Brincadeiras" e "Escola de Príncipes e Princesas Audazes”. Quanto aos sujeitos, contou com três professoras e noventa estudantes do quarto ano do ensino fundamental. Os dados foram coletados por meio da observação participante e de oficinas pedagógicas.

Na observação participante, o observador tem um papel preponderante, uma vez que não é um espectador do fato que está sendo analisado (RICHARDSON et al., 2009). Minayo (2015) acrescenta que, enquanto participante do contexto de observação, o observador tanto é passível de modificar o contexto quanto de ser modificado. Além da aproximação do cotidiano dos sujeitos, para Mónico et al. (2017), há a condição de intervenção nessa mesma realidade, viabilizando o surgimento de novas necessidades em que são desenvolvidas as atividades dos indivíduos.

Por meio da observação participante, foi possível verificar dois aspectos que caracterizavam as atividades em sala de aula: a maior parte das tarefas propostas fazia uso constante do quadro branco e a indisciplina era um fator sempre presente nas turmas pesquisadas, dificultando a relação entre professoras e estudantes.

Por seu turno, as oficinas pedagógicas, segundo Vieira e Volquind (2002), estabelecem um novo tipo de comunicação entre professores e alunos, visto que são constituídas por uma equipe de trabalho em que é possível a contribuição de todos os participantes por meio de suas experiências. Embora o professor seja o dirigente, ele é também um aprendiz. Portanto, as oficinas são um modo de ensinar e aprender realizando algo de forma coletiva. Para isso, é necessário que elas evoquem os seguintes caracteres: o pensar, o sentir e o agir. Infere-se, dessa forma, que as atividades práticas propostas nas oficinas pedagógicas também são passíveis de promover reflexões teóricas advindas da própria realidade.

Com a finalidade de consubstanciar epistemologicamente o processo das oficinas pedagógicas na pesquisa, foi utilizada a abordagem temática intitulada de "Três Momentos Pedagógicos", advogada por Delizoicov e Angotti (2007). Eles propõem momentos pedagógicos a serem desenvolvidos por intermédio de oficinas, cuja execução aponta para três etapas, que são a problematização inicial, a organização do conhecimento e a aplicação do conhecimento. 
PAZ, Anaide Maria Alves da; SILVA, Maria de Fátima Gomes da. O enriquecimento do vocabulário dos estudantes por meio da música em contos de fada no âmbito das práticas pedagógicas dos professores da educação básica

Os dados foram analisados por meio da técnica de análise de conteúdo, seguindo uma perspectiva analítico-descritiva.

3 Contribuições dos contos de fada para o enriquecimento do vocabulário dos estudantes do ensino fundamental

A utilização de contos de fada no Ensino Fundamental traz a lume a importância da contação de histórias, prática em que o professor tem um papel vital, pois deve atuar como um artista que apresenta uma situação com o propósito de envolver os seus ouvintes, os estudantes, na trama que lhes é apresentada. Trata-se de uma enriquecedora estratégia pedagógica, já que possibilita a escuta dos estudantes, fazendo com que a atenção concentrada desenvolva a compreensão e, consequentemente, a interpretação.

Segundo o Referencial Curricular Nacional da Educação Infantil (RCNEI), "a criança que ainda não sabe ler convencionalmente pode fazê-lo por meio da escuta da leitura do professor, ainda que não possa decifrar todas e cada uma das palavras. Ouvir um texto já é uma forma de leitura” (BRASIL, 1998, p. 141). Souza e Bernardino (2011) resgatam Tahan (1964), declarando que há várias formas de se trabalhar a literatura oral no espaço da sala de aula, como, por exemplo, realizar atividades na perspectiva da interdisciplinaridade, haja vista que as condições de tempo e espaço podem suscitar aulas de Linguagem, Matemática e Educação Física. Da mesma forma, referem-se à aprendizagem de valores universais, como liberdade, verdade, justiça, solidariedade, dentre outros, já que as situações narradas nos contos conduzem a criança à reflexão sobre o convívio em sociedade. Essas autoras ainda comentam acerca da possibilidade de deflagrar discussões sobre valores morais, considerando eventos como inveja, traição, covardia e desigualdade, os quais oportunizam a análise crítica de dilemas éticos.

Ainda na ótica de Souza e Bernardino (2011), a história possibilita que as crianças entrem em contato com a utilização real da escrita; conheçam novas palavras, discutindo valores como amor, família e trabalho; e usem a imaginação, desenvolvendo a oralidade, a criatividade e o pensamento crítico, auxiliando na construção da identidade pessoal ou cultural do educando, melhorando seus relacionamentos afetivos interpessoais e abrindo possibilidades para novas aprendizagens nas várias disciplinas escolares, em virtude do seu caráter motivador.

Nessa perspectiva, também é significativo oportunizar aos estudantes a possibilidade de recontar as histórias. Essa prática pode contribuir para que as crianças possam narrá-las com o uso de suas próprias palavras. Contudo, o que é mais preponderante é que elas possam ouvir as suas próprias vozes, sendo levadas a perceber que são capazes de construir sua própria compreensão e 
PAZ, Anaide Maria Alves da; SILVA, Maria de Fátima Gomes da. O enriquecimento do vocabulário dos estudantes por meio da música em contos de fada no âmbito das práticas pedagógicas dos professores da educação básica

que têm a condição de expor a sua própria versão dos fatos. Em suma, na visão de Souza e Bernardino (2011), o contar e o recontar histórias constituem as atividades iniciais na formação do leitor.

No trabalho realizado com contos de fada, é possível trilhar um caminho no qual as curiosidades possam ser exteriorizadas através da recontação de histórias e da apresentação de opiniões acerca delas. Torna-se, então, uma rica oportunidade para professor e estudantes se conhecerem reciprocamente, já que os contos de fada possibilitam a condição de discutir e propor várias alternativas, diante dos impasses que a trama apresenta.

No que concerne ao professor, este deve compreender que o ensino somente lhe é cabível se for resultado de sua própria curiosidade. Essa curiosidade implica inquietude, levando a uma relação dialógica, em que professor e aluno se assumam epistemologicamente curiosos (FREIRE, 2014).

Radino (2001) adverte que a escola, em sua função alfabetizadora, acabou por subestimar a linguagem oral em virtude da valorização do livro e da letra impressa, provocando a ausência de entendimento de que oralidade, leitura e escrita são atividades integradas e complementares. A autora ressalta que é através da linguagem oral que a criança tem o primeiro contato com o texto, estando ele vinculado ou não ao livro.

Apontando outra dificuldade no ambiente escolar, Souza e Bernardino (2011, p. 236) denunciam:

\begin{abstract}
As instituições educacionais recusam um trabalho diferenciado com a leitura, porque a contação de histórias se distancia dos métodos das avaliações. Não se pode medir notas ou conceitos quando contamos ou ouvimos um conto e a escola tem dificuldades em trabalhar com aquilo que não pode ser avaliado. Tal dificuldade é vista até mesmo com a literatura infantil, que perde a sua beleza quando o texto se transforma em uma ferramenta avaliativa, fazendo com que o prazer da leitura se perca com a avaliação.
\end{abstract}

Não obstante, tanto a fluência da oralidade quanto a prática da habilidade escrita devem ser essenciais.

Volubuef (2013) comenta que a literatura culta, apoiada, prioritariamente, na escrita, e a literatura de origem popular, amparada na oralidade, estavam sempre em vias de intercâmbio, fossem em declamação teatral em espaço públicos, nas missas, em banquetes nos castelos, nas feiras e nos mercados abertos, fossem em anotações dos clérigos e de outros estudiosos. Ela cita como exemplo o Saxus Grammaticus, em que as lendas notificadas no século XII foram fontes de inspiração para Shakespeare.

Giordano (2013) aponta que os contos de tradição oral podem causar estranheza, porque o tempo presente é caracterizado como a era das mídias, em que se procura abafar qualidades como memória e saberes de antigamente, resultando inevitavelmente no prejuízo da capacidade de ouvir 
PAZ, Anaide Maria Alves da; SILVA, Maria de Fátima Gomes da. O enriquecimento do vocabulário dos estudantes por meio da música em contos de fada no âmbito das práticas pedagógicas dos professores da educação básica

e contar histórias. A autora descreve a gravidade da situação ao mencionar que "ainda nesse quadro do século XXI, comportamentos antissociais, raivosos, vandalismo [...] revelam os resultados de uma sociedade onde as pessoas já não se encontram para conversar, para contar e ouvir histórias, para trocarem suas experiências [...]” (GIORDANO, 2013, p. 30).

Em sua concepção, os contos de tradição oral promovem competências psicoafetivas que podem contribuir para a promoção de experiências que vão estabelecer os limites necessários, a fim de não serem desenvolvidas atitudes de destruição dos próprios semelhantes. Ela pondera que tais contos enunciam que um final feliz, para se tornar realidade, se inicia com o desejo de viver e do bem viver, isto é, do sucesso em nosso destino. Porquanto, o maravilhoso está no simbólico e não no real, peculiaridade que fortalece e impulsiona para conquistas, libertando o ser humano da existência cotidiana, mesmo que seja momentaneamente.

Giordano (2013) também ajuíza sobre a necessidade de se ter cuidado no que tange à escolha das histórias para crianças e adolescentes, tendo em vista que da mesma forma que podem desencadear libertação, já que trabalham com valores humanos, podem conduzir ao estado de confinamento. Por essa razão, pondera que muitas das histórias, especialmente veiculadas pela mídia, são desprovidas de valores do social, em que a primazia consiste no ter e não no ser. Assim sendo, o sentimento do coletivo parece inexistir, pois as exigências da competitividade produtiva, impostas pelo capitalismo, impelem os indivíduos a se destituírem de suas cargas simbólicas, aquelas que são capazes de assegurar trocas significativas.

As crianças precisam aprender a vencer as hostilidades sem, contudo, ter como alternativa a eliminação do outro, ainda que este lhes cause transtornos. Nesse prisma, a interação deve ensejar condições para que os incômodos sejam suplantados através da solidariedade e do esforço coletivo, tal qual vemos no conto de fada “Os Músicos de Bremen”, no qual os protagonistas da história, a saber, o burro, o cão, o gato e o galo, se unem para garantir a sobrevivência de suas vidas, tendo como ideal constituírem uma banda de sucesso na cidade de Bremen.

Com base nas ideias de Giordano (2013), ainda podem ser ressaltados os ganhos resultantes do ouvir uma história. Nessa ação, destaca-se o favorecimento das relações interpessoais, o estímulo ao prazer e ao desejo, o conhecimento de diferentes culturas e a realização de trabalhos interdisciplinares.

Falconi e Farago (2015) asseveram que os contos de fada estimulam a imaginação e contribuem para o enriquecimento do vocabulário, podendo expandir a linguagem infantil, facilitar a expressão corporal, estimular a inteligência, desenvolver a socialização e a formação de hábitos e atitudes sociais e morais, por intermédio da imitação dos bons modelos e situações existentes nas 
PAZ, Anaide Maria Alves da; SILVA, Maria de Fátima Gomes da. O enriquecimento do vocabulário dos estudantes por meio da música em contos de fada no âmbito das práticas pedagógicas dos professores da educação básica

histórias, e cultivar a memória e a atenção, instigando o interesse e o gosto pela leitura. Desse modo, as crianças organizam seus sentimentos, assegurando o desenvolvimento moral e social.

Para Bergmann e Pires (2008), o texto literário, em especial os contos de fada, pode levar a criança ao desenvolvimento de hábitos que lhes proporcionem uma percepção mais crítica sobre elas mesmas, seu mundo sociofamiliar e a sociedade de um modo geral. Dessa forma, compreendese que o universo vocabular pode ser enriquecido à medida que as crianças tenham acesso a experiências que as façam vencer seus conflitos, muitos dos quais têm origem nos conflitos da sociedade.

Para Silva (2015), a escuta de histórias consiste no início da formação de um bom leitor, tendo em vista uma trajetória de descobertas, de compreensão do mundo, podendo, ainda, levar o sujeito a experimentar momentos de aprendizagem e brincadeira. Em sua dissertação de mestrado, a autora sublinha a contribuição dos contos de fada para a autonomia da criança. Para tanto, defende que "a autonomia implica que a pessoa seja capaz de encontrar um equilíbrio entre as características pessoais e as limitações colocadas pelo meio" (SILVA, 2015, p. 4).

Nesse prisma, ao lidar com a proposição do enriquecimento do vocabulário por meio de contos de fada, sugere-se que o desenvolvimento da autonomia do estudante pode possibilitar uma condição discursiva e uma leitura de mundo. Tal fato significa expor suas ideias e opiniões, bem como aceitar ou discordar de posicionamentos alheios com argumentos coerentes, tendo noção de que o mundo não é limitado ao seu próprio universo geográfico e social.

Porque o conhecimento serve para nos conhecer melhor, conhecer nossas circunstâncias,
para tomar decisões na vida, para adquirir as habilidades e competências do mundo do
trabalho, para tomar parte da vida social, para compreender o passado, o futuro, para se
comunicar, para continuar aprendendo... e não para fazer vestibular (GADOTTI, 2013,
p. 12).

Dessa forma, compreende-se que o enriquecimento do vocabulário dos estudantes não deve estar circunscrito apenas à adição de palavras, pois estas somente terão significado ao serem apropriadas pelos sujeitos na direção de reconhecerem e assumirem a sua própria voz. Por esse motivo, é fundamental que o vocabulário sobre si mesmo, sobre o outro e sobre o mundo seja substancial, sob pena de tornar irrelevante o tripé oralidade, leitura e autonomia.

$4 \mathrm{O}$ enriquecimento do vocabulário dos estudantes do ensino fundamental de escolas públicas de nazaré da mata por meio da música em contos de fada

Nesta pesquisa, a denominação música em contos de fada tem a ver com as narrativas em que a música tem um papel preponderante no enredo das histórias. Assim sendo, foram escolhidos 
os seguintes contos de fada: "O Flautista de Hamelin", “O Músico Maravilhoso” e "Os Músicos de Bremen".

No intuito de verificar se a utilização da música em contos de fada no âmbito das práticas pedagógicas dos professores de escolas públicas municipais de Nazaré da Mata poderia contribuir para o enriquecimento do vocabulário dos estudantes foi realizada uma oficina pedagógica, fundamentada no tripé oralidade, leitura e autonomia. Nessa oficina, foi possível perceber que os estudantes desconheciam as seguintes palavras: burburinho (referente ao conto de fada "O Flautista de Hamelin"); fenda, carvalho, arbustos (referente ao conto de fada "O Músico Maravilhoso"); infatigavelmente, relento, fagulhas, dianteiras, urrava, estampido, ensurdecedor (referente ao conto de fada "Os Músicos de Bremen”).

A oficina foi dividida em três momentos. O primeiro foi destinado a conhecer os instrumentos da orquestra sinfônica. Com base nos instrumentos musicais que os estudantes já conheciam, foi apresentada a fábula musical "Pedro e o Lobo", de Sergei Prokofiev. Foram comunicadas algumas informações básicas sobre o compositor e a peça, visto que se trata de uma obra pedagógica que tem como objetivo apresentar os instrumentos musicais às crianças através de uma história em que cada personagem corresponde a um determinado instrumento. Ainda foi explicado que os instrumentos podem ser tocados sozinhos ou se agruparem em pequenos ou grandes grupos, como é o caso da orquestra sinfônica.

Em todas as escolas, após assistirem ao vídeo "Pedro e o Lobo", foram realizadas algumas indagações aos alunos. Ao serem interrogados se gostaram do que viram, responderam afirmativamente. Quando foram perguntados sobre os instrumentos apresentados, eles citaram os tímpanos como percussão e demonstraram dificuldades em mencionar o clarinete (instrumento de sopro, de palheta simples, formado por um tubo cilíndrico), o oboé (instrumento de sopro, de palheta dupla, cujo corpo tem formato cônico), o fagote (instrumento de sopro, também de palheta dupla, possuindo um tubo maior e mais largo que o clarinete) e as trompas (instrumentos que têm um corpo metálico enrolado várias vezes sobre si mesmo), certamente por não estarem familiarizados com esses instrumentos musicais. Ao serem indagados sobre a parte de que mais gostaram, responderam, quase unanimemente, que foi a captura do lobo.

Para Bergmann e Pires (2008), escutar a experiência do aluno, falar sobre ela e estabelecer relações com a história, tornam-se fundamentais para o desenvolvimento da estruturação do pensamento e das formas de se expressar. Ademais, explorar as histórias através de perguntas orais possibilita que os alunos se expressem perante os demais, apresentando suas emoções e o seu gosto por dadas manifestações culturais em detrimento de outras. 
O segundo momento da oficina pedagógica teve como objetivo exercitar a imaginação e a criatividade por meio da escuta de um conto de fada e da produção de histórias a partir de temas dados. A atividade foi iniciada com a contação da história "Os Músicos de Bremen", a qual foi escutada com bastante atenção nas três escolas. O semblante das crianças demonstrava preocupação, contentamento e alívio durante essa contação de história.

Bergmann e Pires (2008) ressaltam que a criança precisa da magia e do lúdico para entender o mundo que está ao seu redor, já que o ouvir história (itálico das autoras) se constitui em um meio para essa compreensão e para o entendimento de si mesma, ainda que verse sobre emoções e sentimentos que a perturbam e que ela não consiga definir. Segundo as autoras, "ao ouvir histórias os alunos podem sorrir, rir, gargalhar ou chorar com as situações vividas pelos personagens, considerando-se inclusive cúmplices desses momentos" (BERGMANN; PIRES, 2008, p. 53). Nesse sentido, Souza e Bernardino (2011, p. 236) afirmam:

As narrativas estimulam a criatividade e a imaginação, a oralidade, facilitam o
aprendizado, desenvolvem as linguagens oral, escrita e visual, incentivam o prazer pela
leitura, promovem o movimento global e fino, trabalham o senso crítico, as brincadeiras
de faz-de-conta, valores e conceitos, colaboram na formação da personalidade da criança,
propiciam o envolvimento social e afetivo e exploram a cultura e a diversidade.

A leitura (ou audição) do conto de fada apresenta ao leitor ou ao ouvinte a fatalidade da situação, mas, ao mesmo tempo, invoca uma atitude de insubmissão diante do destino que parece ser imutável.

Na sequência da oficina, as crianças foram desafiadas através da seguinte brincadeira: "hoje nós seremos grandes escritores e escritoras, vamos inventar histórias e depois de escrevê-las, vamos apresentá-las ao público". A atividade consistia em criar histórias a partir de temas propostos que deveriam conter alguma referência de música.

Segundo Vigotski (2008), a brincadeira fornece à criança uma nova maneira de desejar, é o seu próprio desejo se relacionando com o "eu" da brincadeira, que é seu papel e a sua regra. "Por isso, na brincadeira são possíveis as maiores realizações da criança que, amanhã, se transformarão em seu nível médio real, em sua moral” (VIGOTSKI, 2008, p. 33).

A última parte da oficina pedagógica foi destinada à sonorização das histórias que foram criadas pelos estudantes. Nesse momento, os alunos foram convidados para irem à frente da sala de aula a fim de mostrarem suas criações, para, em seguida, serem criadas as sonorizações.

A seguir, serão apresentadas peculiaridades da "Escola Castelo das Brincadeiras", considerando o desenvolvimento vivenciado na oficina pedagógica. Ao final do vídeo "Pedro e o Lobo", os estudantes aplaudiram, manifestando satisfação pelo que assistiram e fazendo comentários acerca da apreciação que tiveram a respeito da obra. Entretanto, quanto à elaboração 
PAZ, Anaide Maria Alves da; SILVA, Maria de Fátima Gomes da. O enriquecimento do vocabulário dos estudantes por meio da música em contos de fada no âmbito das práticas pedagógicas dos professores da educação básica

de histórias que deveriam conter algum elemento sobre música, nenhuma apresentou esse aspecto. Assim sendo, os estudantes foram desafiados a produzir uma história coletiva que trouxesse a presença da música, utilizando situações que eles usaram na criação dos seus enredos. Dessa forma, foi elaborada a história intitulada "Mariane e o feiticeiro", apresentada a seguir.

Era uma vez uma estrela que brilhava no céu.

Mariane admirava tanto essa estrela que também queria se tornar uma estrela. Assim, ela pediu ajuda a um feiticeiro.

Eles foram até a floresta e ficaram olhando o céu.

De repente, começou a chover muito, e tão forte que se tornou uma tempestade, caindo um raio sobre uma árvore bem pertinho deles.

Ainda bem que, imediatamente, o feiticeiro fez uma mágica que fez surgir uma cabana para eles se abrigarem.

A chuva durou muito tempo, mas, finalmente o sol surgiu.

Pertinho dali havia um rio que transbordou, devido à chuva, mostrando toda a poluição.

Mariane e o feiticeiro ficaram muito preocupados com a situação do rio.

Voltaram para a vila onde moravam e convocaram todos os moradores para fazer um mutirão de limpeza do rio.

Todos aceitaram!

Deixaram o rio totalmente limpo e, dessa forma, os peixes e as tartarugas voltaram a nadar nas águas.

Mariane ficou tão contente que desistiu de virar uma estrela.

Assim, resolveram fazer uma grande festa, onde Mariane e o feiticeiro convidaram os amigos para fazer uma banda, que até hoje faz muito sucesso.

Esta história foi sonorizada coletivamente, cabendo registrar que houve um envolvimento tão intenso na construção que resultou em um convite para que os estudantes fizessem uma apresentação pública na escola, o que ocorreu na programação da solenidade de encerramento do ano. 
PAZ, Anaide Maria Alves da; SILVA, Maria de Fátima Gomes da. O enriquecimento do vocabulário dos estudantes por meio da música em contos de fada no âmbito das práticas pedagógicas dos professores da educação básica

\title{
Considerações finais
}

Neste estudo, as contribuições da música em contos de fada, em relação ao enriquecimento do vocabulário dos estudantes, estão atreladas ao tripé oralidade, leitura e autonomia, não se restringindo à mera adição de palavras. Assim sendo, ao se investigar sobre o enriquecimento do vocabulário dos estudantes por meio da música em contos de fada no âmbito das práticas pedagógicas dos professores da educação básica, os resultados indicaram que o repertório vocabular foi ampliado. Quando oportunizado aos estudantes o conhecimento de uma fábula musical, que lhes apresentou instrumentos musicais que constituem uma orquestra sinfônica; a possibilidade de conhecer performances musicais; e as condições para ouvir, inventar, sonorizar e contar histórias, eles assumiram posturas que lhes propiciaram escutar, criar e recriar histórias.

A esse respeito, Brito (2003, p. 61) esclarece:

\begin{abstract}
A importância da história no cotidiano das crianças é inquestionável. Ouvindo e, depois, criando histórias, elas estimulam sua capacidade inventiva, desenvolvem o contato e a vivência com a linguagem oral e ampliam recursos que incluem o vocabulário, as entonações expressivas, as articulações, enfim, a musicalidade própria da fala.
\end{abstract}

Especificamente, a oficina pedagógica evidenciou que as vivências interdisciplinares com música e contos de fada podem contribuir para o enriquecimento do vocabulário na perspectiva do desenvolvimento da oralidade, da leitura e da autonomia dos estudantes, aspectos que não devem ser concebidos isoladamente. Em suma, os estudantes ampliaram o vocabulário ao serem capazes de inventar, sonorizar e apresentar suas produções, tanto em sala de aula quanto publicamente, assumindo novas maneiras de pensar e agir.

\section{Referências}

BERGMANN, Leila Mury; PIRES, Maria das Graças Freitas da Rosa. O Flautista de Hamelin: explorando a história. Anuário de Literatura. UFSC, v. 13, n. 2, p. 39-55, 2008. Disponível em: https://periodicos.ufsc.br/index.php/literatura/article/viewFile/2175-7917.2008v13n2p39. Acesso em: 17 ago. 2017.

BRASIL. Secretaria de Educação Fundamental. Referencial Curricular Nacional para a Educação Infantil. Brasilia: MEC/SEF, v. 1, 1998.

BRITO, Teca Alencar de. Música na educação infantil. São Paulo: Peirópolis, 2003.

DELIZOICOV, Demétrio; ANGOT'TI, José André. Ensino de ciências: fundamentos e métodos. 2 ed. São Paulo: Cortez, 2007.

FALCONI, Isabela Mendes; FARAGO, Alessandra Corrêa. Contos de fadas: origem e contribuições para o desenvolvimento da criança. Cadernos de Educação: Ensino e Sociedade. São Paulo, v. 2, n. 1, p. 85-111, 2015. Disponível em: 


\section{Dialogia}

PAZ, Anaide Maria Alves da; SILVA, Maria de Fátima Gomes da. O enriquecimento do vocabulário dos estudantes por meio da música em contos de fada no âmbito das práticas pedagógicas dos professores da educação básica

http://unifafibe.com.br/revistasonline/arquivos/cadernodeeducacao/sumario/35/06042015200 330.pdf. Acesso em: 05 ago. 2017.

FREIRE, Paulo. Pedagogia da autonomia: saberes necessários à prática educativa. 49 ed. Rio de Janeiro: Paz e Terra, 2014.

FREIRE, Paulo. A importância do ato de ler: em três artigos que se completam. 51 ed. São Paulo: Cortez, 2011.

GADOTTI, Moacir. Qualidade na educaşão: uma nova abordagem. Congresso de Educação Básica: qualidade na aprendizagem - Rede Municipal de Ensino de Florianópolis, p. 1-18, 2013. Disponível em: http://www.pmf.sc.gov.br/arquivos/arquivos/pdf/14_02_2013_16.22.16.85d3681692786726aa 2c7daa4389040f.pdf. Acesso em: 06 jan. 2018.

GIORDANO, Alessandra. A arte de contar histórias e o conto de tradição oral em práticas educativas. Construção psicopedagógica. São Paulo, v. 21, n. 22, p. 26-45. 2013. Disponível em: http://pepsic.bvsalud.org/scielo.php?script=sci_arttext\&pid=S1415-69542013000100004. Acesso em: 21 out. 2017.

MINAYO, Maria Cecília de Souza et al. Pesquisa social: teoria, método e criatividade. 34 ed. Petrópolis: Vozes, 2015.

MÓNICO, Lisete. et. al. A observação participante enquanto metodologia de investigação qualitativa. Actas Investigação Qualitativa nas Ciências Sociais. $6^{\circ}$ Congresso Ibero Americano de Investigação Qualitativa, Salamanca, v. 3, p. 724- 733, 2017. Disponível em:

https://proceedings.ciaiq.org/index.php/ciaiq2017/article/view/1447. Acesso em: 06 jan. 2018.

RADINO, Gloria. Oralidade, um estado de escritura. Psicologia em Estudo. Maringá, v. 6, n. 2, p. 73-79, jul./dez. 2001. Disponível em: http://www.scielo.br/pdf/pe/v6n2/v6n2a10.pdf. Acesso em: 15 ago. 2017.

RICHARDSON, Roberto Jarry et al. Pesquisa Social: métodos e técnicas. 3. ed. São Paulo: Atlas, 2009.

SILVA, Ana Rita Fernandes Rodrigues da. A contribuição dos contos de fadas na promoção do conceito de autonomia da criança. 2015. 232f. Dissertação (Mestrado em Educação Pré- Escolar e Ensino do $1^{\circ}$ Ciclo do Ensino Básico) - Instituto Politécnico de Castelo Branco - Escola Superior de Educação, Portugal, 2015.

SOUZA, Linete Oliveira de; BERNARDINO, Andreza Dala. A contação de histórias como estratégia pedagógica na educação infantil e no ensino fundamental. Revista Educere et Educare. Cascavel, v. 6, n. 12, p. 235-249. jul./dez. 2011. Disponível em:

http://saber.unioeste.br/index.php/educereeteducare/article/viewFile/4643/4891. Acesso em: 18 ago. 2017.

TAHAN, Malba. A arte de ler e contar histórias. 2. ed. Rio de Janeiro: Conquista, 1964.

VIEIRA, Elaine; VOLQUIND, Lea. Oficinas de ensino: O que? Por quê? Como? 4. ed. Porto Alegre: Edipucrs, 2002. 


\section{Dialogia}

PAZ, Anaide Maria Alves da; SILVA, Maria de Fátima Gomes da. O enriquecimento do vocabulário dos estudantes por meio da música em contos de fada no âmbito das práticas pedagógicas dos professores da educação básica

VIGOTSKI, Lev Semenovich. A brincadeira e o seu papel no desenvolvimento psíquico da criança. Revista Virtual de Gestão de Iniciativas Sociais. Rio de Janeiro. Jun 2008. Disponível em: https://pt.scribd.com/doc/17391389/Vigotski-A-brincadeira-e-seu-papel-no-desenvolvimentopsiquico-da-crianca-traducao-Zoia-Prestes. Acesso em: 01 fev. 2017.

VOLOBUEF, Karin. Contos de fadas dos Irmãos Grimm. Carta Fundamental. 2013. Disponível em: https://www.cartacapital.com.br/educacao/carta-fundamental-arquivo/contos-de-fadasdos-irmaos-grimm. Acesso em: 22 jun. 2016.

Recebido em: 13 mar. 2020/ Aprovado em: 30 jul. 2020

\section{Cite como}

(ABNT NBR 6023:2018)

PAZ, Anaide Maria Alves da; SILVA, Maria de Fátima Gomes da. O enriquecimento do vocabulário dos estudantes por meio da música em contos de fada no âmbito das práticas pedagógicas dos professores da educação básica. Dialogia, São Paulo, n. 36, p. 428-440, set./dez. 2020. Disponível em: https://doi.org/10.5585/dialogia.n36.16791.

\section{American Psychological Association (APA)}

Paz, A. M. A., \& Silva, M. de F. G. (2020, set./dez.). O enriquecimento do vocabulário dos estudantes por meio da música em contos de fada no âmbito das práticas pedagógicas dos professores da educação básica. Dialogia, São Paulo, 36, p. 428-440.

https://doi.org/10.5585/dialogia.n36.16791. 